\title{
Can Thyroid Hormone Strengthen the Diaphragm in Nonthyroidal Illness?
}

A significant number of critically ill patients requiring mechanical ventilation have diaphragmatic dysfunction, defined as impaired force generation, with some patients developing it within $24 \mathrm{~h}$ after intubation. ${ }^{1}$ Diaphragm dysfunction is associated not only with difficulty in liberation from mechanical ventilation, but with increased mortality as well. ${ }^{2}$ This is widely viewed as a serious problem. A number of causal mechanisms have been proposed, including muscle inactivity, excessive diaphragmatic effort, systemic inflammation, oxidative stress, proteolysis, mitochondrial dysfunction, altered signaling pathways, adverse drug effects, and a disrupted metabolic, electrolyte, nutritional, and hormonal milieu. ${ }^{3}$

It is reasonable to hypothesize that treatments aimed at these mechanisms could improve respiratory muscle function in the short-term and lead to more rapid liberation from the ventilator, shortened ICU stay, reduced mortality, or other, relevant patient-centered outcomes. Thus far, trials have examined phrenic nerve stimulation to prevent muscle atrophy, antioxidant therapy to reduce oxidative stress, anti-inflammatory agents to block the harmful effects from interleukins and other pro-inflammatory mediators, and anti-proteolysis agents. ${ }^{4-7}$ Optimal nutrition and positive protein balance have been shown to decrease diaphragm wasting. ${ }^{89}$ Inspiratory muscle strength training, usually produced using inspiratory threshold loading, may be the intervention best supported by clinical evidence. ${ }^{10}$ Yet, despite these studies, none has proved sufficiently effective for clinical implementation. Aside from mechanism-based therapy, pharmacologic treatments could improve diaphragm function sufficiently to impact the duration of ventilation. In this regard, digoxin, ${ }^{11}$ theophylline, ${ }^{12}$ and levosimendan ${ }^{13}$ have long been known to have salutary effects on the diaphragm.

The challenging fact is that many studies hint at beneficial diaphragm effects, yet no treatment has been shown to improve patient-centered outcomes. Very large trials

\footnotetext{
The authors have disclosed no conflicts of interest.
}

Correspondence: Gregory A Schmidt MD, Department of Internal Medicine, University of Iowa Hospitals and Clinics, 200 Hawkins Drive, Iowa City, Iowa 52242. E-mail: gregory-a-schmidt@uiowa.edu.

DOI: $10.4187 /$ respcare .07400 would be required to show the latter, so perhaps it makes sense to reserve clinical trials for only those treatments that are based on a strong pathophysiological connection to diaphragm dysfunction or those that demonstrate large

See the Original Study on Page 1199

effects on surrogate measures, such as force generation or neuromuscular efficiency.

Several lines of evidence implicate primary hypothyroidism in diaphragmatic weakness. Maximum inspiratory pressure $\left(\mathrm{P}_{\text {Imax }}\right)$ and maximum expiratory pressure $\left(\mathrm{P}_{\mathrm{Emax}}\right)$ are negatively correlated with thyroid-stimulating hormone levels. ${ }^{14}$ In a similar vein, T3 levels are positively correlated with both $\mathrm{P}_{\mathrm{Imax}}$ and $\mathrm{P}_{\text {Emax }}$. Three months of thyroid hormone replacement produces a statistically significant increase in $\mathrm{P}_{\text {Imax }}, \mathrm{P}_{\mathrm{Emax}}$, and vital capacity. ${ }^{15}$ In patients with hypothyroidism, transdiaphragmatic pressure $\left(\mathrm{P}_{\mathrm{di}}\right)$ can be reduced, and severe myopathy has been reported. ${ }^{16}$ Nonthyroidal illness syndrome (NTIS) is commonly encountered in critical illness and is associated with mortality and the duration of mechanical ventilation. ${ }^{17}$ The contribution of NTIS to respiratory failure and whether thyroid hormone replacement improves respiratory muscle function remains unknown, and thyroid hormone replacement in critically ill patients with NTIS has not been shown to improve outcomes. ${ }^{18,19}$ The paper by Bello and colleagues ${ }^{20}$ in this issue of the Journal takes nonthyroidal illness, common in the ICU and potentially linked to respiratory muscle function, and uses diaphragmatic neuromuscular efficiency (NME) as a surrogate end point, seeking to show whether a larger clinical trial is worthwhile.

The investigators enrolled 15 mechanically ventilated subjects with NTIS who failed a spontaneous breathing trial after at least $48 \mathrm{~h}$ of ventilation. All subjects had an esophageal catheter to measure the electrical activity of the diaphragm $\left(\mathrm{EA}_{\mathrm{di}}\right)$. During a brief end-expiratory occlusion, the fall in pressure at the airway opening was measured and assumed to mirror the $\mathrm{P}_{\mathrm{di}}$. NME was calculated as the ratio of the peak negative fall in airway opening pressure and the corresponding $\mathrm{EA}_{\mathrm{di}}$ peak. ${ }^{20}$ If thyroid replacement were to have beneficial effects, one would expect treatment to raise NME (ie, more pressure is produced for similar neural stimulus). In addition, 


\section{EDITORIALS}

NME was used as an index to convert the full $\mathrm{EA}_{\mathrm{di}}$ signal into $\mathrm{P}_{\mathrm{di}}$, allowing the estimation of secondary outcomes including the pressure-time product of the diaphragm per breath $\left(\mathrm{PTP}_{\mathrm{di}} /\right.$ breath $)$ and per minute $\left(\mathrm{PTP}_{\mathrm{di}} / \mathrm{min}\right)$. During the study period, subjects were ventilated using pressure support ventilation guided by neurally adjusted ventilatory assistance and targeted to tidal volumes of $6-8 \mathrm{~mL} / \mathrm{kg}$. All other ventilator settings were left unchanged throughout the study.

Thyroid hormone replacement commenced with an intravenous bolus of $0.4 \mu \mathrm{g} / \mathrm{kg} \mathrm{T} 3$, then a subsequent $24-\mathrm{h}$ infusion of $0.6 \mu \mathrm{g} / \mathrm{kg}$. NME was calculated before T3 infusion, then at 3, 6, and $24 \mathrm{~h}$. No significant differences were seen in NME (the primary outcome measure), $\mathrm{EA}_{\mathrm{di}}$, or PTP $\mathrm{di}_{\mathrm{i}}$ after T3 supplementation, despite normalization of circulating T3 levels. The authors concluded that thyroid hormone replacement did not benefit critically ill subjects with NTIS. ${ }^{20}$ These results do not support further evaluation of the role of thyroid replacement for patients with NTIS and add to other work suggesting that NTIS may be adaptive, rather than pathological.

A strength of the investigation by Bello et $\mathrm{al}^{20}$ relates to how the study population was selected. Identifying subjects already failing a spontaneous breathing trial seems likely to narrow the population to a subset at risk for prolonged ventilation and for whom diaphragm-targeted therapies could be beneficial. Moreover, NME seems a sensible surrogate metric, so that this negative study should leave little enthusiasm for further study of thyroid replacement in this population.

There are several important limitations of this study. First, the sample size is small, so that modest effects could be missed and large effects could be confounded. Second, NME was estimated for only $24 \mathrm{~h}$ after treatment; more delayed effects are possible but would not have been detected due to study design. A further limitation is that NME may not capture fully a hypothetically beneficial impact of thyroid replacement. This is one of the problems in using and choosing surrogate measures of efficacy. Finally, using the fall in airway opening pressure during a brief end-expiratory occlusion, rather than estimating the $\mathrm{P}_{\mathrm{di}}$ with an esophageal balloon, could introduce error.

In conclusion, the results of this study suggest that there is little promise in pursuing thyroid replacement for NTIS with a goal of hastening ventilator liberation. As with several other putative therapies, including some with demonstrated impact on short-term measures of strength or fatigue resistance, translation to clinically meaningful benefits seems a remote dream. The study by Bello and colleagues ${ }^{20}$ points in a helpful direction, however, by showing how to select a high-impact study population and by identifying a broadly applicable surrogate measure. Even when future studies identify candidate treatments, large clinical trials showing improved, patient-centered outcomes (eg, increased ventilator-free days, decreased length of ICU stay, reduced mortality) are needed before these interventions can be introduced into routine care.

\author{
Charles A Rappaport \\ Gregory A Schmidt \\ Division of Pulmonary Diseases, Critical Care, and \\ Occupational Medicine \\ Department of Internal Medicine \\ University of Iowa Hospitals and Clinics \\ Iowa City, Iowa
}

\section{REFERENCES}

1. Demoule A, Molinari N, Jung B, Prodanovic H, Chanques G, Matecki S, Jaber S. Patterns of diaphragm function in critically ill patients receiving prolonged mechanical ventilation: a prospective longitudinal study. Ann Intensive Care 2016;6(1):75.

2. Demoule A, Jung B, Prodanovic H, Molinari N, Chanques G, Coirault $\mathrm{C}$, Jaber $\mathrm{S}$. Diaphragm dysfunction on admission to the intensive care unit: prevalence, risk factors, and prognostic impact: a prospective study. Am J Respir Crit Care Med 2013;188(2):213-219.

3. Supinski GS, Morris PE, Dhar S, Callahan LA. Diaphragm dysfunction in critical illness. Chest 2018;153(4):1040-1051.

4. Mankowski RT, Ahmed S, Beaver T, Dirain M, Han C, Hess P, Martin AD. Intraoperative hemidiaphragm electrical stimulation reduces oxidative stress and upregulates autophagy in surgery patients undergoing mechanical ventilation: exploratory study. J Transl Med 2016;26:14(1):305.

5. Betters JL, Criswell DS, Shanely RA, Van Gammeren D, Falk D, et al. Trolox attenuates mechanical ventilation-induced diaphragmatic dysfunction and proteolysis. Am J Respir Crit Care Med 2004; 170(11):1179-1184.

6. Schellekens WJM, Hees HW, Vaneker M, Linkels M, Dekhuijzen PNR, Scheffer GJ, Heunks LMA. Toll-like receptor 4 signaling in ventilator-induced diaphragm atrophy. Anesthesiology 2012;117(2): 329-338.

7. Azuelos I, Jung B, Picard M, Liang F, Li T, Lemaire C et al. Relationship between autophagy and ventilator-induced diaphragmatic dysfunction. Anesthesiology 2015;122(6):1349-1361.

8. Lewis MI, Lorusso TJ, Zhan WZ, Sieck GC. Interactive effects of denervation and malnutrition on diaphragm structure and function. J Appl Physiol 1996;81(5):2165-2172.

9. Goldspin DF, Morton AJ, Loughna P, Goldspink G. The effect of hypokinesia and hypodynamia on protein turnover and the growth of four skeletal muscles of the rat. Pflugers Archiv Eur J Physiol 1986; 407(3):333-340.

10. Vorona S, Sabatini U, Al-Maqbali S, Bertoni M, Dres M, Bissett B, et al. Inspiratory muscle rehabilitation in critically ill adults: a systematic review and meta-analysis. Ann Am Thorac Soc 2018;15(5): 735-744.

11. Aubier M, Muciano D, Viirès N, Lebargy F, Curran Y, Seta JP, et al. Effects of digoxin on diaphragmatic strength generation in patients with chronic obstructive pulmonary disease during acute respiratory failure. Am J Respir Crit Care Med 1987;135(4):544-548.

12. Murciano D, Aubier M, Lecocguic Y, Pariente R. Effects of theophylline on diaphragmatic strength and fatigue in patients with chronic obstructive pulmonary disease. N Engl J Med 1984;311(6):349-353.

13. Doorduin J, Sinderby CA, Beck J, Stegeman DF, van Hees HW, van der Hoeven JG, et al. The calcium sensitizer levosimendan improves human diaphragm function. Am J Respir Crit Care Med 2012;185(2): 90-95. 


\section{EDITORIALS}

14. Siafakas NM, Salesiotou V, Filaditaki V, Tzanakis N, Thalassinos N, Bouros D. Respiratory muscle strength in hypothyroidism. Chest 1992;102(1):189-194.

15. Laroche CM, Cairns T, Moxham J, Green M. Hypothyroidism presenting with respiratory muscle weakness. Am Rev Respir Dis 1998; 138(2):472-474.

16. Khaleeli AA, Griffith DG, Edwards RH. The clinical presentation of hypothyroid myopathy and its relationship to abnormalities in structure and function of skeletal muscle. Clin Endocrinol (Oxf) 1982; 19(3):365-376.

17. Bello G, Pennisi MA, Montini L, Silva S, Maviglia R, Cavallaro F, Antonelli M. Nonthyroidal illness syndrome and prolonged mechan- ical ventilation in patients admitted to the ICU. Chest 2009;135(6): 1448-1454.

18. Brent GA, Hershman JM. Thyroxine therapy in patients with severe nonthyroidal illnesses and low serum thyroxine concentration. J Clinical Endocrin Metab 1986;63(1):1-8.

19. Becker RA, Vaughan GM, Ziegler MG, Seraile LG, Goldfarb IW, Mansour EH, et al. Hypermetabolic low triiodothyronine syndrome of burn injury. Crit Care Med 1982;10(12):870-875.

20. Bello G, Spinazzola, G, Giammatteo V, Montini L, De Pascale G, Bisanti A, et al. Effects of thyroid hormone treatment on diaphragmatic efficiency in ventilated patients with the nonthyroidal illness syndrome: a physiological study. Respir Care 2019;64(10):1199-1207. 